\title{
Intellectualized testing \& evaluation application based on unmanned test platform
}

\author{
Rongliang Liang*, and Chang Yang \\ China Automotive Research Automobile Inspection Center (Tianjin) co., LTD., Tianjin, China
}

Keywords: electric vehicle, intelligent test, vehicle road test.

\begin{abstract}
Taking three pure electric vehicles as the research object, the energy consumption and acceleration performance of the electric vehicle are tested and evaluated through the use of the intelligent unmanned test platform of the whole vehicle, which ensures that the accurate and high-speed test of the road test can be realized on the basis of no driver in the vehicle. For the electric vehicle energy consumption test, the intelligent unmanned test platform is used for road test, which not only effectively avoids the driver driving the test vehicle for a long time, but also ensures the accuracy and reliability of the test data. According to the test results, the acceleration response and energy consumption test results of three pure electric vehicles are analyzed and evaluated.
\end{abstract}

\section{Foreword}

Road test can provide a more real road environment for pure electric vehicles, and the test results are the most intuitive. The test results can quickly evaluate the performance of the vehicle, and provide reliable test data for parameter calibration, control strategy optimization and development of new sample vehicles. However, from the perspective of enterprise research and development, it is desirable for enterprises to obtain more objective test data through vehicle road tests. At present, the vehicle road test is mostly completed by the driver, so the road test will take human factors into the test result data, thus affecting the objectivity of the test result.

The use of intelligent unmanned technology to replace human drivers to complete complex and dangerous vehicle performance tests is an inevitable demand of the development of the automobile industry. Therefore, this paper adopts the vehicle intelligent test platform for road test of pure electric vehicle, which can provide reliable and accurate control input for the test vehicle, which can not only eliminate the human error involved in the test by the test driver, improve the test efficiency, but also effectively ensure the objectivity and consistency of the data.

\section{Test environment}

\footnotetext{
${ }^{*}$ Corresponding author: yangchang@catarc.ac.cn
} 
The acceleration response and energy consumption test of pure electric vehicles should be carried out in a professional vehicle test site. Long straight dry and flat asphalt pavement should be selected in the test site to ensure that the intelligent unmanned test platform has a long distance to slow down and stop the vehicle after the completion of acceleration test. The longitudinal slope of the test area shall not be less than $1 \%$, and the transverse slope shall not exceed 1\%. The environment parameter requirements are shown in Table 1.

Table 1. Test Environment Parameters.

\begin{tabular}{lc}
\hline Parameter & Environmental Requirements \\
\hline Weather & Dry weather, no precipitation, no snow \\
Visibility & Not less than $1 \mathrm{~km}$ \\
Wind Speed & No more than $5 \mathrm{~m} / \mathrm{s}$ \\
\hline
\end{tabular}

\section{Intelligent unmanned test platform}

\subsection{Test platform equipment specification parameters}

The test instruments used by the intelligent unmanned test platform can withstand road test environment such as road impact and vibration. The test vehicle shall be equipped with braking robot, throttle robot, steering robot, robot controller and GPS inertial navigation gyroscope. Meanwhile, remote control console and corresponding ground base station shall be arranged in the test site. The relevant test equipment specifications are shown in Table 2:

Table 2. Intelligent Unmanned Platform Parameter Requirements.

\begin{tabular}{|c|c|c|}
\hline No. & Equipment & Specification \\
\hline 1 & Test Robot & $\begin{array}{l}\text { 1) The path of straight line and curve can be followed, and the control } \\
\text { precision is no more than } 0.02 \mathrm{~m} \text {; } \\
\text { 2) Speed control range is } 0-140 \mathrm{~km} / \mathrm{h} \text {, and the control accuracy is no } \\
\text { more than } 0.5 \mathrm{~km} / \mathrm{h} \text {; } \\
\text { 3) Control range of deceleration is } 0-10 \mathrm{~m} / \mathrm{s}^{2} \text {, and the control accuracy } \\
\text { is no more than } 0.25 \mathrm{~m} / \mathrm{s}^{2} \text {; } \\
\text { 4) The accuracy of angular velocity should not be greater than } 1 \% / \mathrm{s} \text {; }\end{array}$ \\
\hline 2 & Controller & $\begin{array}{l}\text { 2)System CAN simultaneously collect at least } 10 \text { analog signals in real } \\
\text { time and provide at least } 2 \text { CAN interfaces; } \\
\text { 3) the status parameter data of the test vehicle can be transmitted to the } \\
\text { wireless control in real time and then sent to the remote console }\end{array}$ \\
\hline 3 & RT-3002 & $\begin{array}{l}\text { Real-time measurement of vehicle speed, acceleration, pitching Angle } \\
\text { and other parameter information, RTK mode positioning accuracy up } \\
\text { to } 2 \mathrm{~cm}\end{array}$ \\
\hline 4 & $\begin{array}{l}\text { Remote } \\
\text { Console }\end{array}$ & $\begin{array}{l}\text { The remote console can send relevant instructions to the controller in } \\
\text { the test vehicle in real time, and at the same time can receive test data } \\
\text { and vehicle status in real time. When used in conjunction with the } \\
\text { ground base station, an electronic fence can be built to effectively } \\
\text { ensure the safety and controllability of the test process }\end{array}$ \\
\hline
\end{tabular}

\subsection{Intelligent unmanned test platform device integration}

As shown in Figure 1, 2, vehicle road test with intelligent unmanned test platform integrates the existing braking, steering robots, robot throttle robot, ground stations, inertial navigation gyroscope, such as testing equipment, through the remote console will test conditions and test vehicle path through real-time wireless transmission way to send in a 
test vehicle in the robot controller, the controller receives the command, the real-time control the robot to complete the required instructions, and control the complete test vehicle test accordingly.

Test process, the robot controller inertial navigation gyroscope and the robot can be measured by the relevant data and vehicle state information through wireless transmission remote console, testers can real-time monitoring the whole testing process and the vehicle state information, using GPS and ground base station set up electronic fence can guarantee test vehicles within the test site is allowed, and in a safe control device test vehicles, when there is a sudden situation lead to real-time wireless transmission is interrupted, test vehicles within the security control device can step on the brake pedal in time, ensure the brake of vehicles.

After the test, the controller can wirelessly transmit the entire robot control process, vehicle status information and test results back to the remote console. The tester only needs to analyze the data in the console to complete the evaluation of test results.

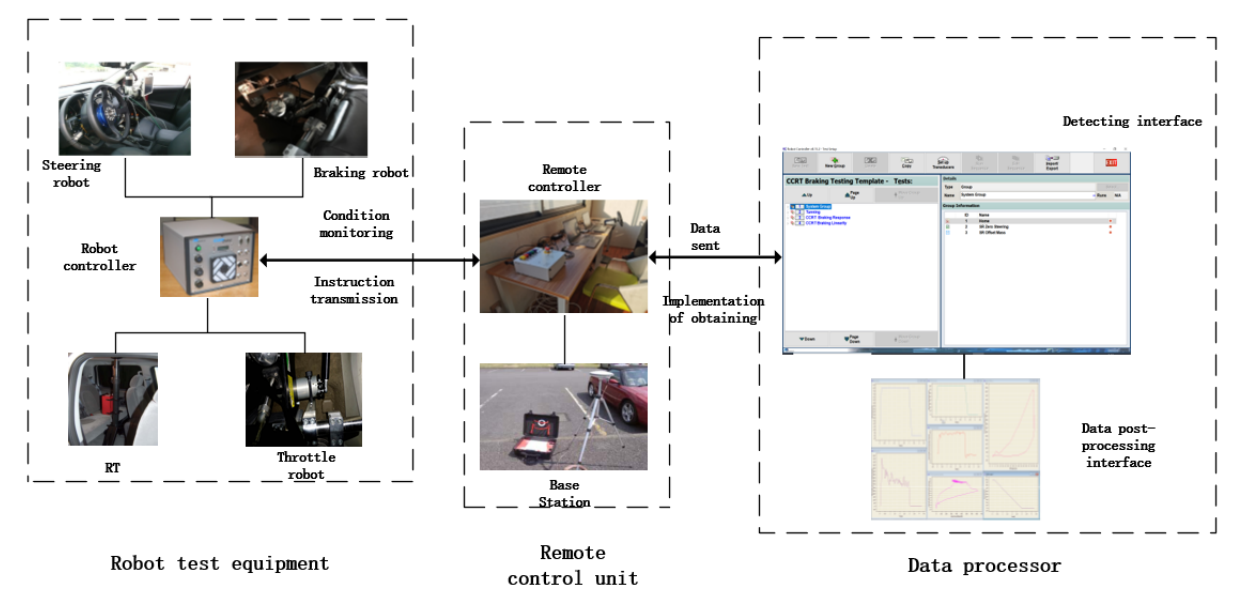

Fig. 1. Structure of intelligent unmanned test platform.

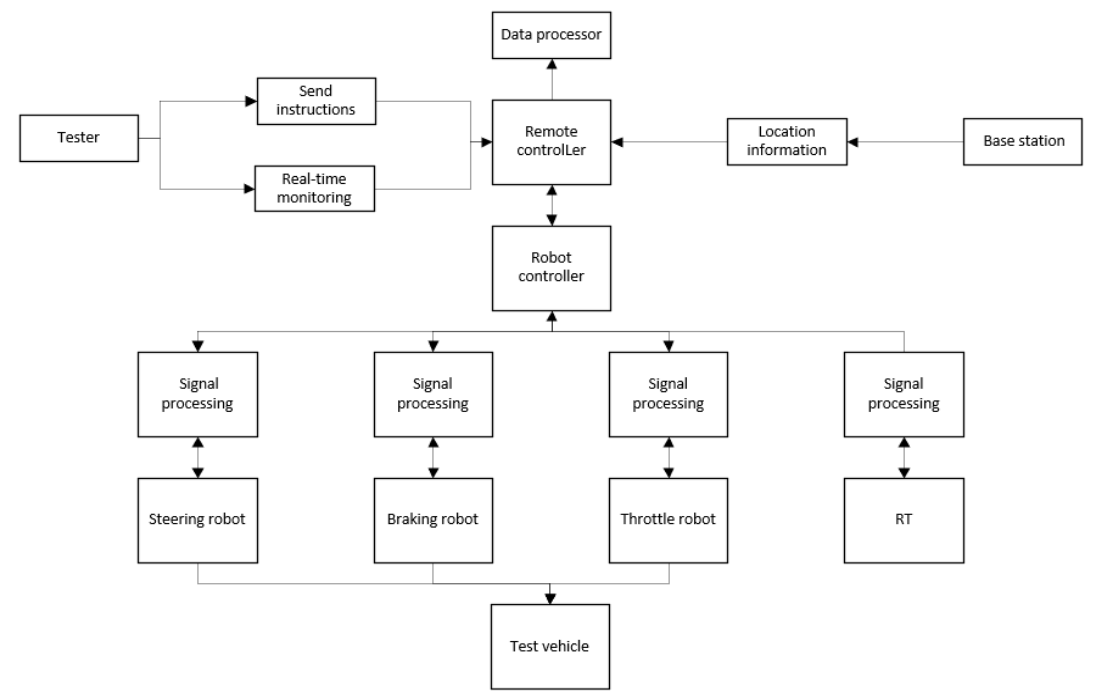

Fig. 2. Structure of intelligent unmanned test platform. 


\section{Road performance test of pure electric vehicle}

The test sample vehicle must charge the power battery SOC to the specified value according to the requirements of the vehicle manufacturer, and load and distribute the test vehicle according to the specified requirements.

\subsection{Accelerator pedal response test}

Before the formal test, the motor and transmission system of the test vehicle should be preheated. The command will be sent to the robot controller through the remote console to control the operation of the vehicle. The vehicle will be stopped after accelerating to $100 \mathrm{~km}$ $/ \mathrm{h}$ and running $3000 \mathrm{~m}$.

The accelerator pedal response test was carried out under full load condition. Will test vehicles according to the testing personnel in remote console writing good tests by wireless transmission way to send to the robot controller, through the ground base station positioning, real-time control of the car's steering robot along a given path, throttle robots will test vehicle speed accelerate to $45 \mathrm{~km} / \mathrm{h}$, with gear taxiing to speed to $40 \mathrm{~km} / \mathrm{h}$, the gas pedal robots in $500 \mathrm{~ms}$ trample accelerator pedal and keep to $100 \%$ opening to record the speed of $100 \mathrm{~km} / \mathrm{h}$ time, repeat the test three times.

Similarly, carry out the response test of the half-load accelerator pedal, record the time, and repeat the above test three times.

Based on the intelligent unmanned test platform, the response test of full-load accelerator pedal and half-load accelerator pedal of A, B and C electric vehicles were carried out respectively. The test results are shown in Table 3:

Table 3. Response time of accelerator pedal.

\begin{tabular}{ccc}
\hline Model & Pedal Response(Full ) & Pedal Response(Half) \\
\hline A & 3.98 & 4.35 \\
B & 4.11 & 4.45 \\
C & 3.80 & 4.15
\end{tabular}

Through data comparison and analysis, it can be concluded that, among the four cars, under the same working condition, the vehicle B achieves the same test vehicle speed, and the acceleration time of car B is shorter, so the response of accelerator pedal is better.

\subsection{Pure electric vehicle energy consumption test}

In the test vehicle load conditions, a pure electric vehicle energy consumption test, specific implementation is as follows: In remote console will test vehicles according to test writing good tests by wireless transmission way to send to the robot controller, through the ground base station positioning, real-time control of the car's steering robot along a given path, throttle robots will test vehicle speed up to $100 \mathrm{~km} / \mathrm{h}$, and keep the speed ring lane five laps at high speed $(8 \mathrm{~km}$ high speed loop). Record the driving time and the voltage and current released during the test.

Relying on the intelligent unmanned test platform, the full-load energy consumption test of electric vehicles of $\mathrm{A}, \mathrm{B}$ and $\mathrm{C}$ types of pure electric vehicles was carried out respectively. Aiming at the economy test of electric vehicle, the instantaneous voltage and current value released by the test vehicle are obtained in real time from the console software, and the relation curve of instantaneous electric power and time is drawn based on the measured data(FIG. 3-5) 
Based on this, the electric quantity released by the test vehicle in the test process is calculated, and the test results are summarized. See Table 4 for the test results.

Table 4. The amount of electricity released during the test.

\begin{tabular}{cc}
\hline Model & Electricity \\
\hline A & 4.885 \\
\hline B & 2.8537 \\
\hline C & 1.217 \\
\hline
\end{tabular}

Rate of energy consumption per unit distance $C=\frac{E}{D}$, To judge the economy of electric vehicles. Where $\mathrm{E}$ is the power released by the test vehicle $(\mathrm{kw} / \mathrm{h}) . \mathrm{D}$ is mileage $(\mathrm{km})$.

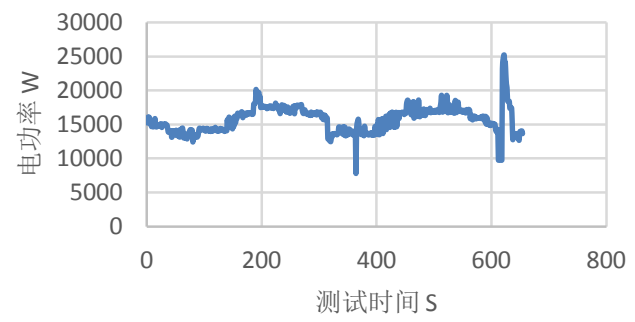

Fig. 3. A Curve of electric power over time.

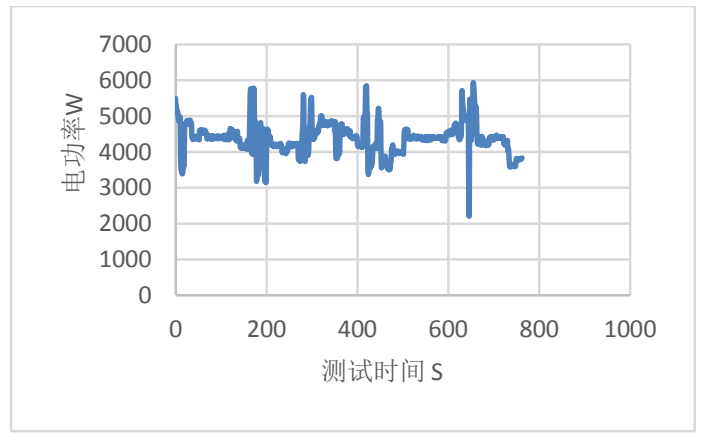

Fig. 4.B Curve of electric power over time.

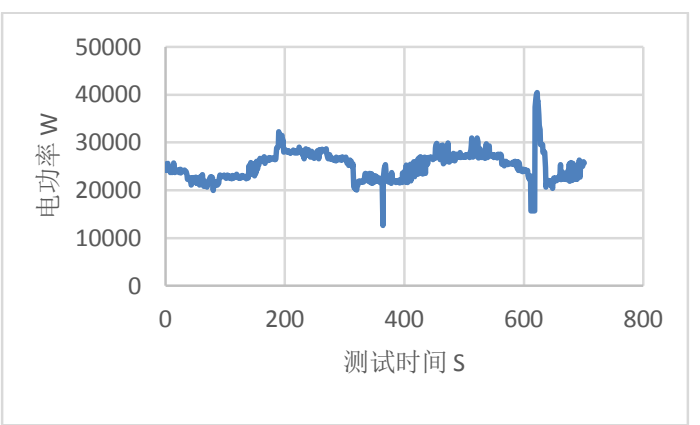

Figure 5 C Curve of electric power over time

As the test was carried out on the high-loop runway, the driving range was $40 \mathrm{~km}$. According to the electric quantity released by each vehicle during the test in table 4 , the unit mileage consumption rate of car $\mathrm{A}$ was $0.1221 \mathrm{kw} / \mathrm{h}$, the unit mileage consumption rate of car B was $0.0713 \mathrm{kw} / \mathrm{h}$, and the unit mileage consumption rate of car C was $0.0304 \mathrm{kw} / \mathrm{h}$, so the economy of car $\mathrm{C}$ was better. 


\section{Conclusion}

(1)In this paper, the response of accelerator pedal and energy consumption of pure electric vehicle are tested by intelligent unmanned test platform. The intelligent unmanned test platform takes the place of the driver to carry out the actual road test of the vehicle, which can obtain more objective test data.

(2)The application of intelligent unmanned test platform in vehicle road test is an inevitable trend of vehicle intelligent test development. The establishment of intelligent unmanned test platform can effectively verify and evaluate the product quality and reliability of vehicle performance of designed vehicles, and provide strong technical support for vehicle enterprise product research and development.

\section{Reference}

1. 方泳龙. 制动理论与设计 $[\mathrm{M}]$. 北京: 国防工业出版社, 2005 .

2. 赵凯辉. 魏朗. 制动器摩擦副摩擦因数研 究. 汽 车 技术. 2009(3): 25-28

3. 刘惟信. 汽车制动系的结构分析与设计计算[M ] . 北京: 清华大学出版社, 2004.

4. 孟德建, 张立军, 余卓平.乘用车制动踏板感觉台架实验研究 [J].汽车工程, 2014,36(12) : 1488-1493.

5. David G Ebert, Richard AKaatz. Objective CharacterizationOfVehicle Brake Feel[ J] , SAE 940311

6. 林志轩, 高晓杰. 制动踏板感觉研究现状 [ J ]. 农业装备与车辆工程, 2007 (06):4-7 .

7. 余志生. 汽车理论 $[\mathrm{M}] 5$ 版. 北京: 机械工业出版社, 2009.

8. 余志生. 汽车理论 $[\mathrm{M}] 5$ 版.北京: 机械工业出版社, 2009.

9. 张静涛. 综合主观评价在整车开发中的应用 [J]时代汽车, 2016(06):11-12.

10. 胡丹. 基于双扩展卡尔曼滤波的汽车状态及路面附着系数估计算法研究 [ D ]. 长 春: 吉林大学 2008

11. 李㥫程. 模式识别原理与应用 $[\mathrm{M}]$. 西安：西安电子科技大学出版社

12. Straub A. DSC(DynamicStabilityContro1)in BMW 7series cars. International Symposium on Advanced Vehicle Control, 1996.

13. Kraft H J. The integrated brake and stability control system of the new BMW 850i. SAE900209. 1990

14. United States National Highway Traffic Safety Administration. FMVSS No. 126 Electronic Stability Control Systems, NHTSA Final Regulatory Impact Analysis. 2007.

15. Masato Abe, Naoto Ohkubo Yoshio Kano. A direct yaw moment control for improving limit performance of vehicle 